\title{
Para Relembrar... Direitos Humanos E POVOS INDÍGENAS
}

\section{Graziele Acçolini ${ }^{1}$}

\begin{abstract}
Resumo
Este artigo pretende apresentar brevemente casos de povos indígenas ameaçados, como a tragédia que atingiu os Ñambiquara do Mato Grosso ocorrida na década de 1970/80 durante a ditadura militar e a situação de desnutrição e dos suicídios que afligem os índios Guarani Kaiowá, população do Mato Grosso do Sul, considerando-os como casos emblemáticos sobre a questão da diversidade cultural em relação aos direitos humanos. 0 objetivo é chamar a atenção para as dificuldades enfrentadas pelos povos indígenas como a ocupação e liberação de terras para fins exploratórios, desmatamentos, queimadas e a tomada de posse pelos latifúndios e a monocultura. Vale lembrar que tais questões não dizem respeito apenas aos povos indígenas, elas também abrangem diretamente determinadas populações e a humanidade em geral, pois se constituem problemas de todos nós.
\end{abstract}

Palavras-chave: Povos indígenas. Diversidade. Direitos Humanos.

\footnotetext{
${ }^{1}$ Profa. Dra. Colaboradora do Departamento de Sociologia e Antropologia, FFC, UNESP/Marília. End. eletrônico: grazieleaccolini@hotmail.com
} 


\section{TO REMEMBER... \\ Human Rights AND INDigenous PEOPLE \\ ABSTRACT}

This article aims to briefly present the cases of threatened indigenous people, as the tragedy that struck the Nambiquara group in Mato Grosso during the 1970/80 decade during the military dictatorship and the situation of malnutrition and suicides afflicting Kaiowá Guarani Indians, population of Mato Grosso do Sul, considering them as emblematic cases on the issue of cultural diversity in relation to human rights. The goal is to draw attention to the difficulties faced by the indigenous people as the occupation and liberation of lands for exploration, deforestation, forest fires and the swearing by estates and the monoculture. It is worth remembering that these issues concern not only to indigenous people, but also cover certain populations directly and humanity in general, because they are our problems too.

Keywords: Indigenous people. Diversity., Human Rights.

\section{Manifesto do Povo Guarani Kaiowá do Mato Grosso do Sul}

Para as autoridades, para o povo brasileiro e pessoas de boa vontade do mundo inteiro mais do que um grito de denúncia e esperança, mais do que dizer que, depois de quinhentos anos de invasão, massacre e derramamento de sangue do nosso povo, estamos vivos lutando por nosso direito de continuar sendo Kaiowá Guarani mais do que dizer que estamos confinados em pequenos pedaços de

terras como em prisões, sofrendo ... violências mais do que denunciar que nossas crianças estão morrendo de desnutrição que nossos jovens estão se suicidando por falta de perspectivas de futuro, e nossos líderes sendo ameaçados e assassinados, queremos exigir nossos direitos à vida digna, a continuar vivendo nosso sistema Guarani, ter autonomia e liberdade em nossas terras e viver em paz. (...). ${ }^{2 *}$

${ }^{2}$ www.direitos.org.br (28/08/2008). 


\section{INTRODUÇÃO}

Teste artigo, pretende-se apresentar, brevemente, alguns casos de povos indígenas ameaçados, considerando as discussões sobre igualdade, 1 diversidade e grupos sociais vulneráveis e o (possível) desenvolvimento autossustentável de tais populações, inseridas no contexto dos Direitos Humanos.

0 objetivo é chamar a atenção, 'relembrar', situações enfrentadas até hoje pelas populações indígenas, situações de clara violação dos direitos humanos, como doenças transmitidas pelos não-índios, epidêmicas na maioria das vezes, conflitos de terras e a consequente violência física e psicológica, devastação ambiental (a posse da terra pelo latifúndio e a monocultura, desmatamentos, queimadas), dentre outras. É interessante 'relembrar' também que tais questões não dizem respeito apenas aos povos indígenas; trata-se de problemas globais que, de fato, envolvem toda a humanidade, mesmo que atingindo de forma indireta uma parcela desta humanidade, por enquanto.

Particularmente, pretende-se discorrer, a partir de um estudo bibliográfico, sobre dois casos que podem ser considerados emblemáticos a fim de ilustrar tais situações: a primeira situação, pertencente a um passado recente, diz respeito aos Ñambiquara do Mato Grosso e a segunda, que será abordada mais de perto, pertencente a um presente atual que diz respeito aos Guarani Kaiowá do Mato Grosso do Sul.

\section{DiReitos Humanos E POVOS INDÍGENAS: BREVE ESBOÇO}

A noção de direitos humanos, sumariamente, se relaciona aos direitos estabelecidos como inerentes à pessoa humana e que visam assegurar sua integridade física e psicológica perante os semelhantes e o Estado. Trata-se de direitos que a sociedade política deve respeitar e garantir. No fundo, trata-se de resguardar valores concebidos como constitutivos da condição humana.

Por direitos humanos ou direitos do homem são, modernamente, entendidos aqueles direitos fundamentais que o homem possui pelo fato de ser homem, por sua própria natureza humana, pela dignidade que a ela é inerente. São direitos que não resultam de uma concessão da sociedade política. Pelo contrário, são direitos que a sociedade política tem o dever de consagrar e garantir (HERKENHOFF apud SAMANIEGO, 2000, p.2). 
Porém, o processo de constituição dos direitos humanos no marco da modernidade possui uma história longa e complexa que, em um âmbito macrohistórico, iniciou-se com o período das grandes descobertas dos séculos XVI e XVII, adentrando o século XVIII, no bojo do movimento iluminista, no qual o "outro" era visto como um selvagem, tornando-se, no século XIX, o primitivo, cuja diferença passa a ser vista não enquanto tal, mas como um estágio evolutivo, a ancestralidade do civilizado, no caso, os europeus.

Esse processo começa a se construir particularmente no período da expansão colonial, momento em que as grandes potências européias estavam em pleno desenvolvimento colonialista, impulsionadas pela Revolução Industrial. 0 processo de colonização como um todo intensificou os contatos interétnicos e a interação entre povos muito diferentes; em seu conjunto, esses contatos foram conduzidos e forçosamente dominados pelas administrações européias. 0 marco da constituição dos direitos humanos se deu no século XX, tendo como pano de fundo as catástrofes da Segunda Guerra Mundial. Como indica Tosi, nos manuais de história, a questão parece simples, como uma construção linear de idéias:

[...] iniciam desde a Magna Charta Libertatum da Inglaterra do século XIII, passando pela Revolução Gloriosa Inglesa do século XVII, até a Revolução Americana e Francesa do século XVIII para concluir finalmente com a Declaração Universal das Nações Unidas do século XX. A Europa e o ocidente aparecem, assim, como o espaço onde progressivamente, ainda que com contradições, se forja a emancipação do homem, que é, posteriormente, estendida a toda a humanidade como modelo a ser seguido. 0 resto do mundo constitui o agente passivo, marginal, é o "outro" que não é "descoberto", mas "ocultado" como afirma Henrique Dussel [...] (TOSI, 2002, p. 25).

Ou seja, durante esses séculos, desde as descobertas do século XVI e de todo processo colonizador até 0 advento da Declaração Universal dos Direitos Humanos, proclamada pela ONU em 1948, pós Segunda Guerra Mundial, pode-se observar que é no contexto da expansão européia que a doutrina dos direitos humanos foi sendo construída a partir da confluência de várias correntes de pensamento, como a do liberalismo, do socialismo e do cristianismo social:

Os redatores tiveram a clara intenção de reunir, numa única formulação, as três palavras de ordem da Revolução Francesa de 1789: liberdade, igualdade e fraternidade. Desta maneira, a Declaração Universal reafirma o conjunto dos direitos das revoluções burguesas (direitos de liberdade, ou direitos civis e políticos) e os estende a uma série de sujeitos que anteriormente estavam 
deles excluídos (proíbe a escravidão, proclama os direitos das mulheres, defende os direitos de estrangeiros, etc.); afirma também os direitos da tradição socialista (direitos de igualdade, ou direitos econômicos e sociais) e do cristianismo social (direitos de solidariedade) e os estende aos direitos culturais (TOSI, 2002, p. 29-30).

Querdizer, acaracterística dessa históriaé, ainda no discurso contemporâneo e apesar dos avanços, a visão eurocêntrica que se coaduna com a noção de progresso ocidentalmente construída, tendo como base a civilisation da Revolução Francesa e sua ideologia expansionista e homogeneizante para os demais povos do mundo.

Ainda assim, dentre os caracterizadoscomo direitos humanos fundamentais, tem-se os artigos 1 e 55 da Carta das Nações Unidas que institui os princípios da autodeterminação dos povos, da não discriminação e o princípio da promoção da igualdade, aspecto que se põe como um avanço inquestionável no que tange à questão dos povos indígenas.

De acordo com o princípio da autodeterminação dos povos, o direito dos povos e nacionais à livre determinação é um requisito prévio para o exercício de todos os direitos humanos fundamentais. 0 princípio da não discriminação, por sua vez, determina que o pleno exercício de todos os direitos e garantias fundamentais pertence a todas as pessoas, independentemente de raça, sexo, cor, condição social, genealogia, credo, convicção política, filosófica ou qualquer outro elemento arbitrariamente diferenciador (SAMANIEGO, 2000, p. 10).

No Brasil, resumidamente, a história dos direitos humanos se coaduna, direta ou indiretamente, com a história das Constituições e os respectivos contextos sócio-políticos que as marcaram. Em relação aos povos indígenas, a Constituição de 1988 reconhece e assegura claramente os modos de vida que caracterizam as sociedades indígenas e suas terras tradicionais. Além disso, o Estatuto do Índio já garantia, em 1973, seus direitos civis e políticos, direitos dentre outros ratificados internacionalmente pela Declaração Universal dos Direitos dos Povos Indígenas, promulgada em 2007. Inclusive um dos pontos de grande relevância deste documento é a mudança de ênfase dos "direitos universais individuais" para os "direitos humanos coletivos", concepção que caracteriza tais sociedades. Essas preocupações devem muito aos movimentos dos próprios povos indígenas, desde a década de 1980, com a atuação de entidades, associações e lideranças indígenas. 
Sem intenção de aprofundar, a partir desse esboço, pode-se notar que no parâmetro dos direitos humanos diretamente e dos direitos que tratam das sociedades indígenas, aqui sumariamente apontados, as normas internacionais e nacionais garantem a manutenção de modos de existência distintos da ocidental/ nacional, como é o caso das populações indígenas no Brasil.

Porém, o que se assiste é o desrespeito a tais direitos, o que poderá ser visto a partir dos casos, exemplos dentre outros, que serão abordados tendo como foco a questão de expropriações de terra indígenas: os Ñambiquara e a tragédia que os assolou na década de 1970 e o caso dos índios Guarani-Kaiowá, exemplo contemporâneo do descaso com que ainda são tratados os povos indígenas e a relação destes com seus territórios tradicionais.

\section{Os Índios Ñ Nabiquara E OS GUARANI-KaIOWÁ: DOIS CASOS DE EXPROPRIAÇÕES DE TERRAS}

Os povos indígenas possuem histórias de contato com segmentos da sociedade colonial, posteriormente nacional há séculos; histórias de sujeição e violência, tanto pelas armas, quanto pela "cruz", objetivando a liberação e ocupação do território para fins exploratórios. É interessante mencionar Beatriz Perrone-Moisés (1992, p.129) quando a antropóloga coloca que: "se não se pode tratar a todos os indígenas do Brasil do mesmo modo, é porque eles não reagem à colonização do mesmo modo". Frase que demarca as especificidades que existem entre as próprias sociedades indígenas do contato com as frentes de expansão e seus agentes com quem foram e são obrigadas a se deparar e enfrentar.

Os grupos Ñambiquara são conhecidos desde o século XVIII quando da ocupação predatória de seus territórios, atual Mato Grosso, em virtude da descoberta de ouro na região, como na chapada de São Francisco Xavier. Desde então, iniciase um processo de tentativa de aldeamento de tais grupos, tarefa que não obteve sucesso. Mesmo mantendo contatos esporádicos com seringueiros e quilombolas, foi no século XX com a criação do SPI, tendo Rondon à frente, que se estabeleceram os primeiros contatos pacíficos com tal população indígena. Das décadas de 1940 a 1970, os Ñambiquara sofreram grandes perdas devido a epidemias, especialmente os grupos que se encontravam próximos à construção das linhas telegráficas.

Na década de 1960, iniciou-se a construção da estrada que liga Cuiabá a Porto Velho no estado de Rondônia, a BR 364, dividindo ao meio o território Ñambiquara. Nesta mesma década, também foi criada pelo governo militar de 
Costa e Silva a reserva Ñambiquara na região entre os rios Juina e Camararé, região cujo solo é extremamente pobre e árido. 0 objetivo era o de aglutinar em um só lugar os índios e liberar terras para empreendimentos agropastoris. Os grupos do vale do Guaporé foram os mais atingidos e todas as tentativas de transferência, executadas à época pela Funai, para a reserva demarcada foram frustradas.

Nas décadas seguintes (1970-1980), alguns grupos Ñambiquara, cujas terras não haviam sido demarcadas, foram transferidos do rico território do Guaporé para a estéril Chapada dos Paresis, de onde retornaram (os que não morreram por lá) em um estado de desnutrição, na maioria, irrecuperável. No território desocupado pelos índios, foi utilizado pelas empresas agropastoris para desmatamento o "agente laranja". Assim, com o retorno de parte da população Ñambiquara para suas autorreconhecidas terras, muitos terminaram morrendo, não por desnutrição, mas por envenenamento do solo, da água, da fauna e da flora.

0 escândalo foi tão grande que os militares, numa tentativa de abafar 0 caso, trataram de atender, por exemplo, os Terena do Mato Grosso do Sul que reivindicavam a instalação de rede elétrica em suas aldeias.

A visibilidade de tal ação estatal seria interessante para o governo militar, posto que a população Terena possui uma história de contato com a sociedade colonial/nacional que difere de outras, como comentado por Perrone-Moisés (1992), pelo envolvimento que há séculos mantém com a sociedade regional, em especial a partir da Guerra do Paraguai.

Para os Terena, a Guerra do Paraguai não representou somente a passagem para um estágio de contato intenso com a sociedade brasileira, mas representou também a consciência deste povo de pertencerem a uma esfera maior de relações até então inexistente, a idéia de pertencerem a uma "nação" e todas as questões políticas e sociais que tal situação acarreta. Nesse sentido, pode-se interpretar 0 atendimento dessa reivindicação por parte dos militares como uma ação calculada, nada inocente e que incidiria de forma positiva internacionalmente, projetando um tratamento "igualitário" que aleivosamente se ofereceria aos povos indígenas.

A população Ñambiquara conta com aproximadamente 1.600 pessoas (dados de 2008), espalhadas por nove Terras Indígenas descontínuas que comportam uma ínfima parcela do extenso território tradicional e que de forma alguma respeitam o modo de vida Nambiquara, suas atividades sazonais e a 
divisão em pequenos bandos liderados por um chefe. Como bem retrata LéviStrauss,

[...] 0 ano Ñambiquara divide-se em dois períodos distintos. Na temporada chuvosa, de outubro a março, cada grupo mora sobre uma pequena eminência dominando o curso de um riacho; os indígenas ali constroem cabanas toscas com galhos ou palmas. [...] plantam e cultivam roçados onde figuram sobretudo a mandioca (doce e amarga), diversas espécies de milho, fumo, ás vezes feijão, algodão, amendoim e cabaças. [...] No início da estação seca, a aldeia é abandonada e cada grupo se desfaz em vários bandos nômades. Durante sete meses, esses bandos vão vagar pelo cerrado, em busca de caça: bichinhos sobretudo, tais como larvas, aranhas, gafanhotos, roedores, cobras, lagartos; e de frutas, grãos, raízes ou mel selvagem, em suma, tudo o que pode impedi-los de morrer de fome (LÉVI-STRAUSS, 1996, p.259).

Quer dizer, a questão da extensão do território é fundamental para a manutenção do modo de vida Ñambiquara, tanto em termos de aquisição de alimentos, quanto em relação à manutenção de uma visão de mundo própria de povos caçadores-coletores, como é o caso desta sociedade. Para os Ñambiquara, como para outros povos indígenas, limitar o território significa alterar a forma de se relacionar com a natureza e, concomitantemente, alterar sua especificidade cultural.

Nesse sentido, apesar da declaração pretensamente universal dos Direitos Humanos, o que já remete a algumas questões como a própria categoria universal, que se pauta na ótica da sociedade ocidental e que carrega intrinsecamente uma noção também própria, relativa, do que seja igualdade e diversidade; apesar da Constituição Federal brasileira ter consagrado de forma expressa os direitos dos povos indígenas; apesar da Convenção 169 da Organização Internacional do Trabalho (OIT) recomendar aos governos o respeito à importância que possui para determinadas culturas a relação com os territórios que ocupam ou utilizam de alguma forma e, (o "apesar" mais recente) apesar da Declaração dos Direitos dos Povos Indígenas proclamada em 13/09/2007 pela Assembléia Geral da ONU, o que se assiste é o desrespeito e o descaso constante às leis e condutas asseguradas, mas não executadas efetivamente.

No presente, a situação vivenciada pelos Kaiowá no sul do Mato Grosso do Sul pode ser categorizada como hedionda, exemplo atual de violação dos direitos humanos "universais" dentre outros tantos que se pode aventar como forma não só de registro, mas de denúncia. 
Vivendo em pequenas áreas indígenas superlotadas, demarcadas de forma descontínua e cercadas por latifúndios agropastoris que se apropriaram especialmente a partir da década de 1950 - de parte do território do Mato Grosso do Sul, os Kaiowá é um dos povos mais afetados pela intrusão devastadora do que se pode chamar, sem a pretensão de aprofundar o tema, de "capital". Com o passar do tempo, a população foi se acomodando nas reservas à medida que não tinham mais onde se estabelecer frente à ocupação do território.

Com esse processo de ocupação de território e uma política de liberação de terras a partir da aglutinação de parte dos Kaiowá às áreas destinadas, essa população começou a vivenciar dois sérios problemas: a desnutrição, em especial de crianças, diretamente associada aos índices de mortalidade infantil e o suicídio.

Os Kaiowá ocupavam um extenso território de mata fechada no atual MS, (entre os rios Apa, serra de Maracajú, rio Brilhante, rio Ivinhena, rio Paraná, rio Iguatemi e na fronteira com o Paraguai) (VIETTA e BRAND, 2004, p.220-221).

Os pequenos núcleos populacionais, formados por uma ou algumas poucas famílias extensas, base organizacional dos Kaiowá, chefiadas porseu tekoharuvicha (tekoha, comunidade, aldeia; chefe de aldeia), ou Ñanderu (nosso pai), mantinham entre si diversas relações matrimoniais. Esses núcleos eram relativamente autônomos e o que os caracterizava era a mobilidade que mantinham, ocupando dessa maneira todo seu amplo território. Tais deslocamentos, na maioria das vezes, eram gerados por conflitos entre as parentelas e pela busca de expansão de território, o que retrata o próprio modo de ser Guarani Kaiowá.

Segundo Katya Vietta e Antonio Brand (2004) e também Lévi Marques Pereira (2003), as primeiras frentes de expansão alcançaram-nos a partir de 1880 com a chegada da Companhia Mate Laranjeiras e algumas poucas fazendas de gado. Nesse período, apesar do contato e do trabalho dos Kaiowá na colheita da erva mate, sua estrutura social se viu pouco alterada, posto que tal trabalho era realizado por famílias que se deslocavam em grupos para alcançar distantes ervais. Também se deve mencionar que esta companhia não questionou a posse das terras ocupada pelos índios.

Nas décadas de 1910 e 1920, o governo federal reconheceu legalmente oito reservas para que os núcleos Kaiowá que se encontravam dispersos fossem instalados em locais permanentes liberando assim o restante das terras; nem todos 
os núcleos foram à ocasião convencidos a ocupar as reservas (VIETTA e BRAND, 2004).

A nova situação de reserva alterou profundamente o padrão tradicional de assentamento das parentelas e aldeias fazendo com que perdessem autonomia sobre sua forma própria de vida, seu ñhandereko, ou Kaiowáreko (PEREIRA, 2003).

Mas, os problemas se agravaram sobremaneira na década de 1940, quando a região gradativamente começa a ser atingida pelas frentes pastoril e agrícola e, com o encerramento do contrato com a Cia. Mate Laranjeira, as terras públicas são consideradas devolutas e passaram a ser vendidas a particulares forçando muitas aldeias Kaiowá a desocupar os locais onde estavam instaladas. Além disso, tem-se a política implementada em 1943 por Getúlio Vargas, a Colônia Agrícola Nacional de Dourados que objetivava 0 acesso à terra para famílias de colonos e migrantes de outras regiões. Schaden (1974 apud VIETTA e BRAND, 2004, p.222) relata que, com o impacto da ocupação maciça do território, os índios "passaram a executar danças religiosas com o fito de apressarem a destruição do mundo...".

Com a frente de colonização, além da ocupação das terras e o deslocamento forçado dos núcleos de parentelas, cresceu sobremaneira a incidência de tuberculose, febre amarela, DSTs, sarampo, alcoolismo, dentre outras, agravada pelo alto índice de desnutrição e a falta de assistência pelo órgão responsável.

A partir da década de 1950, as fazendas de gado começaram a tomar posse da região, incluindo as áreas de mata fechada e atingindo diretamente as parentelas. A aglutinação dessas parentelas nas reservas chegou ao auge nas décadas de 1970 e 1980, com o surgimento de novos problemas e situações inéditas para os índios, como a superpopulação e a sobreposição de parentelas e lideranças, ocasionando conflitos internos e ao mesmo tempo fortalecendo a autoridade de não-índios sobre tal realidade. Vale lembrar que tal processo continua até a atualidade. Como relata Pereira,

Na situação de reserva, os líderes locais estão sempre procurando novos canais de legitimação e fortalecimento político, uma vez que as configurações das redes de apoio político interno se tornam em muitos casos inoperantes. Qualquer chefe de posto da Funai, agente indigenista, missionário, ou mesmo dono de venda que tenha convívio algum tempo com lideranças de uma reserva Kaiowá pode relatar eventos nos quais foi solicitado a opinar ou atuar como mediador em conflitos internos. Na maioria das vezes, esses agentes não 
dispõem da mínima condição de compreensão dos fundamentos das demandas para as quais foram acionados, e muito menos das apropriações internas a que a sua interferência está sujeita (PEREIRA, 2003, p. 143).

Quer dizer, o aumento da população pode potencializar o surgimento de novos líderes político-religiosos e acarretar conflitos e divisões de cunho individual, ao contrário do que ocorria com aldeias que ainda viviam distantes umas das outras, onde as tradições poderiam ser enfatizadas e impedir que soluções individualistas e atrativos da dita "civilização" tivessem mais êxito, ou seja, seguindo de fato a expressão petei rami'y, que significa "não é cada um por si” ou "conviver" (GODOY, 2003).

É nesse cenário dramático que se põe o quadro de mortalidade por desnutrição e os suicídios, problemas relacionados à falta de terras, à demarcação descontínua das áreas e também a falta de acesso aos recursos naturais, posto que nascentes e cursos de água se encontram, muitas vezes, dentro dos latifúndios.

Sociedades caçadoras-coletoras, como a dos índios Kaiowá, têm seu modo de produção pautado no que se chama de economias de "punção", ou seja, a economia em que o homem retira da natureza somente o necessário para a sobrevivência do grupo. Assim, os animais caçados e os produtos coletados são submetidos a rígidas regras, a partir dos ritos e dos tabus cuja preocupação é a reprodução do sistema adaptativo e, por conseguinte, a preservação do próprio grupo.

Aqui se tem a importante figura do Trickster, personagem arcaica, herói cultural que ensinou as técnicas de sobrevivência e entidade mítica cuja função simbólica é a de se colocar como reequilibrador das relações homem-natureza. As ações do trickster se pautam no modelo da prática de "reposição negativa", ou seja, numa economia baseada na punção, o homem não devolve à natureza de forma direta o que dela retirou, como na agricultura pelas sementes plantadas. Nesse sentido é que o trickster cuida dos recursos da natureza punindo quem extrapola. E na visão de mundo da comunidade, a morte da caça, por exemplo, é "compensada" com a morte dos seres humanos. É isso que se poderia chamar de "trocas negativas" ou "reposição negativa":

[...] Admitindo-se que este princípio seja a necessidade de estruturação de uma representação das trocas ou relações, poderíamos considerar num dos pólos a comunidade humana e, no outro, o mundo exterior (a Natureza) de que a humanidade tira seu sustento. As atividades de subsistência poderiam 
ser representadas como relações negativas (de "punção" na terminologia de Meillassoux) uma vez que os seres humanos "arrancam" da Natureza os animais caçados e os produtos coletados. ... as próprias ações dos "tricksters" são, em linhas gerais, o modelo superestrutural dessa prática de "reposição negativa (CARVALHO, 1985, p.177-179).

Isso parece demonstrar que, numa sociedade baseada neste tipo de economia, a limitação do território em termos de extensão e em termos de acesso aos recursos dessa natureza significa a própria desestruturação de uma visão de mundo, de uma filosofia de vida. A caça se integra aos ideais de conduta masculina, de liderança, prestígio através do conhecimento dos animais e da floresta que demonstra a virilidade de um jovem e o habilita ao matrimônio. A roça, mba`ety (mbàe, que significa "coisa" e ty, "agrupamento de coisas") também é parte de um tekoha (aldeia), principalmente a lavoura de milho que estimula os encontros rituais relacionados a rezas e benzimentos. Nesse caso, um tekoha sem plantação não tem como exprimir o Ara Pyau (Ano Novo) para seus integrantes (GODOY, 2003).

Sobre os suicídios, as primeiras notícias entre os Kaiowá surgiram em 1985-1986. Coincide com o período de dinamização econômica do Mato Grosso do Sul, por conta da separação do Estado de Mato Grosso, em 1978, que provocou um redimensionamento fundiário, levando vários outros tekoha (comunidades, aldeias) a serem expulsos de seus locais tradicionais (os que ainda se encontravam fora das áreas indígenas) e levados para as reservas já existentes, superlotando-as cada vez mais (VIETTA e BRAND, 2004).

0 suicídio pode ser visto como uma ação individual e social, visto que tradicionalmente não se tem notícias de suicídio entre os Kaiowá e os casos possuíam muitas características semelhantes, como a de estar relacionada principalmente aos jovens. Dessa forma, o suicídio parece se colocar como um sintoma, uma recusa a uma situação dada; parece representar uma solução para uma situação na que os princípios e valores Kaiowá não podem se realizar.

0 grande contingente de suicídios ocorreu na área de Dourados, adentrando a década de 1990. Nesta área, a lado do município de mesmo nome, a situação econômica ainda é muito grave, com um alto índice de alcoolismo, interferência de religiões como o protestantismo e o pentecostalismo além, claro, da igreja católica presente no contexto indígena desde a colonização, exploração da mãode-obra indígena e a falta de terras para a plena realização do modo de vida 
kaiowá. Enfim, nesse contexto de exploração, fome, violência, como ser um verdadeiro Kaiowá? Como concretizar os princípios éticos que regem o Kaiowáreko?

Assim, o suicídio parece exprimir o desejo de viver de acordo com este kaiowáreko, com sua ética e valores próprios; uma manifestação do apego a determinada visão de mundo.

Como expõe M. Marta Azevedo,

[...] a terra para os Kaiowá é uma terra específica, para plantarem ... para realizarem sua cultura. Ñande Ivy é a nossa terra, entendida como nosso mundo, do qual fazem parte nossos antepassados (já que quando se morre se volta para a terra) e nossos filhos. Portanto, essa concepção específica de terra, e não qualquer terra e de qualquer tamanho, é o esteio da identidade deste povo [...] (AZEVED0, 1991, p. 20).

Apesar de o suicídio parecer, em princípio, peculiaridade dos Kaiowá, já que não atinge os Guarani Mbyá e nem os Ñhandeva, como também não atingiu a população Terena que convive com os Kaiowá, a situação de transformação social, estrutural, não constitui, de forma alguma, característica desse povo, mas uma situação que envolve todos os povos indígenas brasileiros. Situação essa que aparentemente envolve somente a questão de terras, mas de fato envolve a questão da manutenção de modos de vida distintos da ocidental dominante.

\section{À GUISA DE CONCLUSÃo}

0 caso dos índios Ñambiquara, mesmo que o episódio relatado tenha transcorrido há algumas décadas, bem como o caso dos Guarani-Kaiowá que ainda hoje vivem em áreas minúsculas, muitas delas praticamente nas periferias das cidades do sul do Mato Grosso do Sul, convivendo com a desnutrição e mortalidade infantil e a falta de expectativa de vida digna para seus jovens, demonstram o quanto é necessário fazer para que o instituído legalmente faça parte de ações efetivas que resolvam, de forma justa, por exemplo, a questão relaciona às terras indígenas. Apesar desse artigo se ater a apenas esses dois exemplos, tais situações, com suas particularidades, poderiam ser estendidas à maioria dos povos indígenas brasileiros que passam pelas mesmas ou semelhantes vicissitudes.

Diante dos casos expostos que possuem como ponto em comum a expropriação das terras tradicionais, parecem pertinentes as colocações de Dom 
Pedro Casaldáliga, bispo emérito da Prelazia de São Félix do Araguaia (Mato Grosso), em entrevista cedida ao jornalista João de Barros (2008), não só em relação aos povos indígenas brasileiros e latino-americanos, mas em relação aos humanos em geral e todos aqueles "outros", fauna e flora, água e terra, que com estes são obrigados a conviver,

Enquanto houver latifúndio não haverá paz. Latifúndio por definição é acumulação, privilégio e exclusão. É monocultura. É tóxico, antinatural, inumano, contra a vida. É o inimigo número um da América Latina. A história do Brasil é a das capitanias, que nada mais eram do que latifúndios. Hoje, se misturam: além das terras, há o latifúndio do capital internacional, do capital financeiro, dos meios de comunicação, e até o latifúndio da política - 0 avô é senador, o pai deputado federal e o filho deputado estadual. Como se acaba com isso? Só com a revolução (BARROS, 2008).

Mais que isso, a situação das terras, dos latifúndios, (inclusive os latifúndios políticos como bem colocou Casaldáliga em relação ao Brasil) envolve a discussão sobre o tipo de direitos (civis, políticos, econômicos, sociais) de que se está tratando; em que marco essas questões se colocam e são elaboradas. Mesmo com o direito coletivo a autodeterminação dos povos, povos esses subjugados pelo processo colonial, parece que o direito a que se refere a Declaração é o direito individual, e o direito de propriedade parece ser o primeiro direito econômico a ser reconhecido, ou seja, os direitos abarcados e legitimados são elaborados no marco da sociedade ocidental ou, como bem aponta Boaventura de Sousa Santos (GANDIN e HYPOLITO, 2003), "ocidental liberal" presente no discurso dominante dos direitos humanos.

Assim, a "universalidade" contida no discurso sobre os direitos humanos, direitos esses que nem ao menos contaram com a participação da maioria dos povos do mundo, iguala a todos, iguala inclusive (ou tenta) a alteridade, a diversidade humana; não reconhece na prática visões de mundo distintas do modelo ocidental dominante e totalizador; não reconhece o "outro" (DUSSEL, 1977).

Como argumenta Boaventura de Sousa Santos,

[...] Há a idéia de que, sendo todos iguais, é fundamental que se dê uma redistribuição social, nomeadamente ao nível econômico, e é através da redistribuição que assumimos a igualdade como um princípio e como prática. Naturalmente que este princípio não reconheceu a diferença como tal. A política de igualdade, baseada na luta contra as diferenciações de classe, 
deixou na sombra outras formas de discriminação étnicas, de orientação sexual ou de diferença sexual, etárias e muitas outras. É a emergência das lutas contra estas formas de discriminação que veio a trazer a política da diferença. E a política da diferença não se resolve progressisticamente pela redistribuição: resolve-se por reconhecimento [...] (GANDIN e HYPOLITO, 2003, p.12-13).

Assim, parece contraditório assegurar e legitimar supostas "universalidades" nas que, de fato, encontram-se diferenças, diferenças essas que deveriam ser enfocadas como possíveis alternativas de vida e convivência no planeta e com 0 planeta e não como formas minoritárias que tendem, sob a direção da sociedade ocidental representada pelos Estados majoritários no sentido político-econômico, a sucumbir e se homogeneizar, proposta implícita na Declaração como em tantos outros documentos que se propõem a assegurar a dignidade e a autonomia das comunidades humanas. Nesse sentido, parece que o pensamento sobre os Direitos Humanos (inclusive nos meios acadêmicos) ainda não transcendeu algumas discussões, como a de que é impossível compreender como universal o que se construiu a partir de uma única ótica.

Dessa forma, as situações aqui brevemente relatadas que envolvem as sociedades indígenas e que podem ser estendidas a outros grupos e sociedades considerados minoritários do ponto de vista político, servem não só como denúncia, mas também como demonstração de que esse modelo é dominante, mas não é 0 único existente a ser seguido e implementado.

Por essa perspectiva, a da diversidade humana, pode-se apontar que as sociedades indígenas representam uma esperança ao planeta, visto que seu modo de produção e sua visão de mundo são responsáveis pela convivência com a natureza e não apenas pela manutenção da natureza, visão que vigora sob a lógica do como explorar melhor sem destruir!

\section{REFERÊNCIAS}

AZEVED0, Maria Marta. Suicídio Kaiowá. Revista Terra Indígena. CEIMAM (Centro de Estudos Indígenas Miguel A Menéndez), v.8, n.58, Araraquara, 1991, p. 6-28.

BARROS, João de. 0 Araguaia já está morrendo: entrevista com Pedro Casaldáliga. Caros Amigos, São Paulo, ano 12, n. 137, 2008, pp.38-43. Disponível em: <www. carosamigos.com.br> Acesso em: 09 abril 2010. 
CARVALHO, Silvia M. S. 0 trickster como personificação de uma práxis. Perspectiva, n. 8, São Paulo, 1985, pp.177-186.

DUSSEL, Enrique D. Filosofia da libertação na América Latina. São Paulo: Loyola, 1977.

GANDIN, Luis A. e HYPOLITO, Álvaro M. Dilemas do nosso tempo: globalização, multiculturalismo e conhecimento: entrevista com Boaventura de Sousa Santos. Currículo sem Fronteiras, v.3, n.2, 2003, pp.5-23. Disponível em: <www. curriculosemfronteiras.org/vol3iss2articles/boaventura.htm> Acesso em: 09 abril 2010.

GODOY, Marília G.G. O misticismo Guarani Mbya na era do sofrimento e da imperfeição. São Paulo: Terceira Margem, 2003.

LÉVI-STRAUSS, Claude. Tristes trópicos. São Paulo: Companhia das Letras, 1996.

LEVCOVITZ, Sergio. Kandire: o paraíso terreal. 0 suicídio entre os índios Guarani do Brasil. Rio de Janeiro: Ed. Espaço e Tempo, 1998.

PEREIRA, Levi Marques. Assentamento e formas organizacionais dos Kaiowá atuais. Revista Tellus, ano 3, n.4, Campo Grande, 2003, p. 137-145.

PERRONE-MOISÉS, Beatriz. Índios livres e índios escravos. Os princípios da legislação indigenista do período colonial (séculos XVI a XVIII). In: CUNHA, Manuela C (Org.). História dos índios no Brasil. São Paulo: Companhia das Letras, 1992.

SAMANIEGO, Daniela Paes Moreira. Direitos humanos como utopia. Jus Navigandi, Teresina, ano 4, n. 46, out. 2000. Disponível em: <http://jus2.uol. com.br/doutrina/texto.asp?id=76>. Acesso em 28 de maio 2010.

SCHADEN, Egon. Aculturação indígena. São Paulo: Ed. Da Universidade de São Paulo, 1969 .

TOSI, Giuseppe. História e atualidade dos direitos do homem. In: Polícia e Democracia: desafios à educação em direitos humanos. Recife: Ed. Bagaço, 2002, p. 25-49.

VIETTA, Katya e BRAND, Antonio. Missões evangélicas e igrejas neopentecostais entre os Kaiowá e os Guarani em Mato Grosso do Sul. In: WRIGHT, Robin (org.). Transformando os deuses - Vol. II. Campinas: Ed. da Unicamp, 2004. 